\title{
Telegram como um Recurso de Apoio Metodológico no Curso de Ciências Contábeis: Relato de Experiência
}

\section{Telegram as a Methodological Support Resource in the Course of Accounting Sciences: Experience Report}

\author{
André Juliano Machado*a; Eliza Adriana Sheuer Nantes ${ }^{\mathrm{a}}$ \\ aUnopar, Programa de Pós-Graduação Stricto Sensu em Metodologias para o Ensino de Linguagens e suas Tecnologias. PR, Brasil. \\ *E-mail: andremachado.prof@gmail.com
}

\begin{abstract}
Resumo
Este trabalho tem como objetivo proceder um relato de experiência na disciplina de Contabilidade Tributária do Curso de Graduação presencial em Ciências Contábeis, tendo como recurso de apoio metodológico a utilização do Telegram, um aplicativo caracterizado como um serviço de mensagens instantâneas baseado na nuvem, em que é permitido ao usuário troca de mensagens, fotos, vídeos e arquivos de qualquer tipo, possibilitando a comunicação entre professor e aluno no compartilhamento de informações e materiais de aula. Trata-se de um estudo descritivo, com o objetivo de retratar as características de utilização do Telegram como suporte de apoio metodológico, levado a campo com abordagem qualitativa e que se ancora nas intersecções entre metodologias ativas e ações didático-pedagógica. O instrumento de coleta de dados foi o registro das interações realizadas no Telegram. Utilizou-se de categorias de análises, sendo essas: descrever, informar, confrontar e reconstruir. O início desta pesquisa ocorreu com a criação de um canal dedicado ao compartilhamento de informações e materiais da disciplina. Os resultados deste estudo indicaram um avanço na socialização e interatividade, promovendo discussões sobre os temas da disciplina, ampliando as capacidades de retorno de informações e reflexões do professor e suas práticas, o que favorece amplamente as mudanças. Conclui-se que, o uso de metodologias ativas de ensino realizadas, por meio deste aplicativo, contribuem no campo de conhecimento, quanto às potencialidades do Telegram, na socialização, na comunicação, na mediação e ao estímulo para a continuidade dos estudos.
\end{abstract}

Palavras-chave: Ensino. Ensino Híbrido. Contabilidade Tributária. Letramentos Digitais.

\begin{abstract}
This work aims to provide an experience report in the Tax Accounting discipline of the on-site undergraduate course in Accounting Sciences, using Telegram as a methodological support resource, an application characterized as a cloud-based instant messaging service, where the user is allowed to exchange messages, photos, videos and files of any kind, enabling communication between the professor and the student in the sharing of information and class materials. This is a descriptive study, with the objective of portraying the characteristics of using Telegram as a support for methodological support, carried out in the field with a qualitative approach and anchored in the intersections between active methodologies and didactic-pedagogical actions. The data collection instrument was the recording of interactions carried out on the Telegram. Analysis categories were used, namely: describe, inform, confront and reconstruct. The beginning of this research took place with the creation of a channel dedicated to sharing the discipline's information and materials. The results of this study indicated an advance in socialization and interactivity, promoting discussions on the subjects of the discipline, expanding the professors'ability to return information and reflections and their practices, which largely favors changes. It is concluded that the use of active teaching methodologies carried out, through this application, contributes to the field of knowledge, regarding the potential of Telegram, in socialization, communication, mediation and encouragement in the continuity of studies.
\end{abstract}

Keywords: Teaching. Hybrid Teaching. Tax Accounting. Digital Literacies.

\section{Introdução}

Com o avanço das Tecnologias Digitais de Informação e Comunicação (TDIC), as práticas sociais humanas sofreram alterações significativas, o que já havia sido preconizado pelos estudos de Lévy (1998), quando o estudioso já destacava que, com o advento do ciberespaço, haveria novas formas de conhecimento; a cibercultura possibilita novos modos de acesso ao saber, a tal ponto que as formas de comunicação/ interação humanas seriam, metaforicamente, como "um grande hipertexto móvel, labiríntico, com cem formatos, mil vias e canais", um espaço em que, segundo ele, "os membros da mesma cidade compartilham grandes números de elementos e conexões da megarrede comum" (LÉVY, 1998, p.185).

Vive-se em tempos de hipermodernidade, em que as relações sociais e pedagógicas contemporâneas passam por grandes transformações, as quais estão sendo impulsionadas pela apropriação das diferentes tecnologias digitais (TD) e redes de comunicação digitais (RCD). As novas formas de comunicação digital estão assumindo seu protagonismo, rompendo práticas e alterando comportamentos até pouco tempo considerados inabaláveis. Em função de sua importância, segundo Moreira (2018), ignorar o uso dessas tecnologias seria o mesmo que desprezar o seu potencial para propiciar a inovação, a transformação e a modernização. 
Apesar da facilidade de utilização das tecnologias digitais, algumas visões mais populares tendem ao exagero, pois não podem servir de camuflagem às tradicionais instruções didáticas e currículos mais ou menos obsoletos. Neste ponto, deve ser considerado que a ênfase não pode estar focada somente na tecnologia, mas sim nas condições que afetam a apropriação tecnológica, traduzindo-se em incremento significativo na educação, tanto no sentido quanto em sua qualidade.

É importante trazer essa reflexão à tona, pois a simples introdução da tecnologia não produz mudanças nas práticas pedagógicas. Portanto, se faz necessário alterar a forma como se pensa a educação com o interesse claro de maximizar os benefícios introduzidos por essas inovações.

São novos modos de ser, de se relacionar, de aprender que surgem associados às novas tecnologias, novas linguagens, novos gêneros. Com essas mudanças são modificados também as concepções de ensino e aprendizagem, em que se apropriar do conhecimento e transformá-lo em novos saberes se torna fator determinante no papel do professor frente às práticas significativas de ensino com destaque para um ensino pautado nos gêneros discursivos.

No entanto, com o surgimento do novo Corona vírus (COVID-19) e o agravamento dos problemas de saúde em âmbito mundial, todo o processo de transformação das práticas pedagógicas tem sido negligenciado ou até ignorado. Em função das restrições impostas para a diminuição do contágio desta nova doença, várias Instituições de Ensino têm passado por mudanças dolorosas, implicando em enormes desafios e alterações estruturais.

A transformação de práticas pedagógicas, com a inclusão das tecnologias digitais (TD), leva um tempo considerável para que seja implementada e alcance seu devido potencial. No entanto, segundo Moreira e Schlemmer (2020), atualmente, o que ocorre é a transposição das metodologias e práticas pedagógicas tradicionais para a realidade online, sendo agora conhecida por uma forma de ensino remota de emergência.

Em grande parte dos casos, as tecnologias digitais estão sendo utilizadas apenas como meros instrumentos, transmitindo informações geradas pelo professor aos seus alunos, sem nenhum incremento ou alterações em suas práticas pedagógicas. No primeiro momento, isso se faz necessário em função urgência para o enfrentamento desta Pandemia, mas se deve continuar com as mudanças em práticas para se atingir uma educação de qualidade que se defende.

Considerando o contexto histórico dos problemas da área da saúde pelo qual se está passando, são trazidos algumas reflexões de professores que, por motivo de força maior, viramse frente à frente com a utilização de novas tecnologias, sem o processo de adaptação de suas práticas de ensino. Para isso, faz-se necessário delimitar os conceitos do Ensino Remoto e a Educação a Distância, estabelecendo suas principais diferenças e como essas estão influenciando as decisões diariamente.

Diante de tal contexto, foi necessário que fossem pensadas novas ações e estas requereram adaptações na prática pedagógica do pesquisador, entre essas a implementação de recursos que auxiliassem a transpor o espaço geográfico, na busca pela interação possível, diante do contexto e das tecnologias disponíveis e da alteração da própria arquitetura em que ocorria o ensino presencial.

O objetivo do estudo foi proceder um relato de experiência sobre a utilização do Telegram, enquanto recurso de apoio metodológico, na disciplina de Contabilidade Tributária, no curso de Graduação. Para tanto, inicia-se apresentando os pressupostos epistemológicos, a seguir, tem-se o aporte metodológico que ancora as ações do trabalho; encerrando o diálogo com a discussão e análise dos dados.

\section{Material e Métodos}

A metodologia de pesquisa selecionada se utiliza da abordagem qualitativa que, segundo Creswell (2014, p.67), permite ao pesquisador desenvolver "uma atividade situada que localiza o observador no mundo", consistindo em "um conjunto de práticas materiais interpretativas que tornam o mundo viável". O tipo de pesquisa foi a descritiva exploratória, pois segundo Bauer (2017), nessa o pesquisador procura explorar e mensurar com cientificidade um determinado lócus de pesquisa, permitindo uma análise de dados com interpretação mais detalhada.

Quanto ao lócus, foi uma Universidade privada, localizada no Norte do Paraná, na qual o pesquisador atua como docente, junto ao curso de Ciências Contábeis. A disciplina selecionada foi a de Contabilidade Tributária, pois proporciona múltiplas atividades contábeis e estudos complementares que podem ser desenvolvidos pelos alunos durante a realização do curso, o que possibilitou o contato direto com vinte alunos com os quais foram desenvolvidas atividades com o uso do Telegram.

Assim, a fim de relatar a experiências vividas pelo pesquisador, visando demonstrar as facilidades e dificuldades vivenciadas entre professor e aluno, por meio de um canal de comunicação criado no Telegram, com o intuito de relatar como foi experienciar a utilização do Telegram, enquanto recurso de apoio metodológico, na disciplina de Contabilidade Tributária, opta-se pela linha do professor reflexivo, da qual emergem as categorias de análise.

Para tanto, recorre-se aos estudos de pesquisadores que trabalham com a linha do professor que procede uma reflexão crítica sobre a sua própria ação, como os estudos de Smyth (1992) e Liberali (2004), de forma que se têm as seguintes categorias de análise: (a) descrever: consiste na descrição das ações docentes para organizar o planejamento da sua prática de pedagógica; (b) informar: trata-se do momento em que o professor tem como foco informar como o construto teórico elegido dialogou com as ações propostas, imbricando teoriaprática; (c) confrontar: assumindo-se que toda teoria, na prática, tende a ser adequada/reformulada, seja por intempéries, seja por lacunas da pesquisa, neste momento o pesquisador 
relata o que foi necessário adequar; (d) reconstruir: momento de o pesquisador (re)pensar, (re)construir, (re)encontrar possíveis caminhos, em sua prática metodológica.

\section{Resultados e Discussão}

\subsection{Ensino Híbrido}

Segundo Guri-Rosenblit (2009), com o advento das TDIC foram criados meios e condições que contribuíram para as principais mudanças na $\mathrm{EaD}$, passando pelas concepções teóricas, as abordagens pedagógicas, sua finalidade e processos de avaliação de aprendizagem dos alunos. Geralmente, utilizado com o mesmo significado da "Educação a Distância", o "e-learning" é visto como uma nova versão da $\mathrm{EaD}$, em que as atividades são mediadas pelas TDIC. Além disso, a literatura internacional utiliza uma série de outros termos para definir as diversas formas da nova $\mathrm{EaD}$, como por exemplo, web-based education, on-line education, virtual classroom, distributed learning, etc. No Brasil, não há uma definição explícita para o termo e-learning, por esse motivo, "Educação a Distância" tem sido usado para designar o ensino a distância mediado pelas TDIC.

De acordo com Valente (2014), outra modalidade de e-learning é quando parte das atividades são realizadas totalmente a distância e parte é realizada em sala de aula, caracterizando o que tem sido denominado de ensino híbrido, misturado ou blended learning.

$\mathrm{Na}$ área educacional, o Instituto Clayton Christensen (CHRISTENSEN; HORN; STAKER, 2013) realizou uma pesquisa em mais de oitenta organizações, selecionando 100 educadores que atuavam com o ensino híbrido, cabendo aos atores envolvidos realizar os apontamentos sobre suas percepções, na ótica do aluno, sobre essa forma de ensino. Como resultado, a compilação destes enunciados subsidiou a definição do termo, tendo como arcabouço a teoria da inovação disruptiva:

O ensino híbrido é um programa de educação formal no qual um aluno aprende, pelo menos em parte, por meio do ensino on-line, com algum elemento de controle do estudante sobre o tempo, lugar, modo e/ou ritmo do estudo, e pelo menos em parte em uma localidade física supervisionada, fora de sua residência (CHRISTENSEN; HORN; STAKER, 2013, p.7).

No Brasil, acredita-se que essa seja a modalidade que pode introduzir mudanças no ensino presencial e nas disciplinas ou cursos realizados a distância. De acordo com Moran (2015), o modelo predominante de educação a ser utilizado pelas Instituições de Ensino será o blended, permitindo a união entre o ensino presencial e o ensino a distância, transformando os cursos presenciais em semipresenciais, principalmente, na fase mais adulta de formação que se encontra no Ensino Superior.

Ainda, no país, os estudos de Bacich e Moran (2015, p.45) destacam que "a educação sempre foi misturada, híbrida, sempre combinou espaços, tempos, atividades, metodologias, públicos", contudo, esse processo se torna mais perceptível em função de fatores como "a mobilidade e a conectividade", o que tende a possibilitar um "ecossistema mais aberto e criativo". Isso é comprovado pelo fato do blended learning ter evoluído para o ensino híbrido, essa evolução se fez necessária em função da ampliação do seu alcance, permitindo introduzir um conjunto mais rico de estratégias ou dimensões de aprendizagem.

Já nos estudos de Hoffman (2011, p.2), suas proposições defendem que "nem tudo que é intitulado blended learning o é realmente". Na sequência, este autor apresenta sua própria definição, na qual considera que "B-learning é usar as melhores metodologias disponíveis para um objetivo específico, incluindo ensino a distância, instrução em sala de aula (presencial), suporte de atividades tanto em papel como on-line e soluções".

De acordo com Sunaga e Carvalho (2015, p.144), o papel da tecnologia, no contexto da aprendizagem híbrida, é agregar identidade e voz ao aluno, auxiliando a personalização de sua aprendizagem, transformando a educação massificada em outra que permite ao aluno aprender em seu ritmo e de acordo com os conhecimentos previamente adquiridos, o que possibilita aos estudantes avançarem mais rapidamente.

Apresentando uma definição bastante completa para essa modalidade de ensino e uma taxonomia de formas de uso que é bem ampla, Staker e Horn (2012) definem blended learning como um programa de educação formal que mescla momentos em que o aluno estuda os conteúdos e instruções usando recursos on-line, e outros em que o ensino ocorre em uma sala de aula, interagindo com outros alunos e o professor. Quando realizado de forma on-line o aluno dispõe de meios para controlar quando, onde, como e com quem vai estudar. No caso do blended learning, o conteúdo da disciplina é desenvolvido de forma mais específica ao invés de usar qualquer material que o aluno possa acessar pela internet. Já na parte presencial, o aluno deve, necessariamente, contar com a supervisão do professor, valorizando as interações interpessoais que são complementares às atividades on-line.

De acordo com Staker e Horn (2012), o ensino híbrido pode ser categorizado em quatro modelos de ensino híbrido ou blended: flex, blended misturado ou "A la carte", virtual enriquecido e rodízio.

No primeiro modelo denominado flex, a âncora do processo de ensino e de aprendizagem é o conteúdo e as instruções que o aluno trabalha via plataforma on-line. A flexibilidade neste modelo está contida no tipo de suporte que ele recebe na situação presencial, podendo ser um apoio substancial de um professor certificado, supervisionando as atividades em grupo ou projeto desenvolvido pelo aluno.

O segundo modelo denominado como blended misturado ou "A la carte", consiste no cenário, no qual uma ou mais disciplinas são cursadas de forma totalmente on-line para complementar as disciplinas cursadas presencialmente. Alguns cursos de graduação já utilizam este modelo, em sua grade curricular, pois algumas disciplinas de interesse do aluno são oferecidas somente de forma on-line.

Já no modelo virtual enriquecido, o aluno cursa as disciplinas de forma on-line, mas de forma concomitante, pode 
realizar atividades presencialmente, como exemplo se têm as experiências práticas e laboratórios. A diferença deste modelo se comparado ao blended misturado, está no fato de a maior parte do ensino acontecer de forma on-line, complementado com poucas atividades presenciais.

$\mathrm{Na}$ última categoria, denominada como modelo rodízio ou rotação, é proporcionado ao aluno, alternar ou circular por diferentes modalidades de aprendizagem. Este modelo pode ser dividido em quatro subgrupos. $\mathrm{O}$ primeiro subgrupo denominado como rodízio entre estações proporciona ao aluno a possiblidade de circular por diferentes estações dentro da sala de aula, denominadas como estação de aprendizagem on-line, desenvolvimento de projeto, trabalho em grupo ou interagindo com o professor, tirando dúvidas. Um segundo subgrupo consiste no rodízio entre laboratórios, cabendo ao aluno circular entre os diferentes espaços do campus, como o laboratório de atividades on-line, ou laboratórios para o desenvolvimento de práticas específicas. Já no terceiro subgrupo se tem o rodízio individual, em que o aluno se utiliza de diferentes modalidades de aprendizagem de acordo com horários prefixados.

No quarto e último subgrupo, denominado de sala de aula invertida (flipped classroom), o conteúdo e as instruções são estudados on-line pelo aluno, pois a sala de aula passa a ser o local para trabalhar os conteúdos já estudados, com a realização de atividades práticas, resolvendo problemas e projetos, discutindo em grupo e socializando conhecimentos.

Por ser considerado um conceito ainda recente, seus fundamentos e sentidos para aplicação, no contexto educativo, são ainda diversos. No entanto, o termo eLearning, anteriormente definido nesta pesquisa, em função de avanços tecnológicos e às transformações sociais introduzidas pelas tecnologias digitais, "tornou-se uma derivação ou evolução natural da EaD” (MOREIRA; SCHLEMMER, 2020).

Contribuindo ainda mais aos conceitos de ensino híbrido, Moreira e Schlemmer (2020) afirmam que, por outro lado, necessita-se de total atenção ao design instrucional dos ambientes virtuais de aprendizagem, para atingir os objetivos e cumprir os requisitos e as exigências de acessibilidade, de forma a "promover novas interações e aprendizagens socialmente relevantes e contextualizadas.

\subsection{Ensino Remoto}

Essa forma de ensino é definida pelo termo remoto, que significa distante no espaço e se refere ao distanciamento geográfico. O Ensino Remoto ou Aula Remota, segundo Moreira e Schlemmer (2020), se configura como "uma modalidade de ensino ou aula que pressupõe o distanciamento geográfico de professores e estudantes".

Atualmente, a sociedade tem sido afetado pelos efeitos da Pandemia causada pelo vírus COVID-19, mais comumente denominado como Corona vírus. A impossibilidade da presença física de estudantes e professores, nos espaços destinados ao ensino, propiciou o surgimento do ensino remoto emergencial, como "alternativa para a continuidade das atividades educativas, visando minimizar os prejuízos decorridos da suspensão das aulas presenciais" (SANTO; DIAS-TRINDADE, 2020).

Neste cenário, considerando todas as incertezas resultantes desta Pandemia, segundo Tomazinho (2020), essa forma de ensino também pode ser denominada como emergencial, "pois todo o planejamento pedagógico realizado para o ensino presencial foi engavetado, dando lugar a um planejamento improvisado e realizado em tempo real." Dessa forma, gestores e professores estão sendo obrigados a tomar decisões intempestivas, pois em nenhum estudo ou reflexão a respeito do futuro da educação, foram cogitadas as possibilidades em que alunos e professores, por motivos de força maior, fossem impedidos de frequentarem suas salas de aula.

Segundo Moreira e Schlemmer (2020), nessa modalidade, há uma transposição do ensino presencial físico para os meios digitais, considerando os mesmos cursos, currículos, metodologias e práticas pedagógicas. Mesmo havendo um distanciamento geográfico, o processo continua sendo igual ao ensino presencial, ou seja, centrado no conteúdo, ministrado pelo mesmo professor da disciplina presencial, com ênfase no compartilhamento de informações, ao mesmo tempo, de forma síncrona, seguindo os mesmos princípios do ensino presencial, embora apresente deficiências em relação ao mesmo.

Os estudos de Santo e Dias-Trindade (2020, p.163) trazem informações neste mesmo sentido ao afirmarem que a "mera transposição para o disruptivo espaço virtual de práticas pedagógicas exitosas no ensino presencial não se configura como educação a distância”. Esta afirmação traz reflexões importantes sobre como a Educação a Distância evoluiu e hoje essa demanda especificidades que não podem ser desconsideradas, pois seu processo de construção vem sendo considerado o planejamento do design instrucional/educacional e modelagem pedagógica até sua implementação, para atingir o objetivo final da educação de qualidade.

No ensino remoto, a comunicação é predominantemente bidirecional, constitui-se em uma videoaula protagonizada pelo professor da disciplina de forma expositiva, por meio de sistemas de web conferência (SANTO; DIAS-TRINDADE, 2020).

Nesta modalidade, o foco está nas informações e em suas formas de transmissão, fortemente ancoradas em plataformas conhecidas como o Google Meet, Zoom e Microsoft Teams. A lógica do controle é predominante, segundo Moreira e Schlemmer (2020, p. 9), "tudo que é concebido e disponibilizado é registrado, gravado e pode ser acessado e revisto posteriormente." Cabe aqui fazer uma analogia, pois em algumas versões, o ensino remoto assemelha-se ao ensino a distância do século passado, mas agora a única diferença é o acréscimo das tecnologias digitais em rede.

Dessa forma, professores do ensino presencial estão sendo arremessados em ambientes virtuais de aprendizagem sem formação prévia, resultando em um processo educativo deficiente, prejudicando a formação dos estudantes. Nesse sentido: 
[...] a mediação pedagógica online pressupõe o desenvolvimento de competências digitais dos professores que extrapolam a técnica e se relacionam, sobretudo, com a reflexão crítica da utilização das tecnologias digitais como elemento estruturante de formas de ser, pensar e agir (SANTO; DIAS-TRINDADE, 2020, p.163).

Outros fatores importantes devem ser considerados, pois quando se está falando sobre o Ensino Remoto e as vantagens apresentadas por meio das conferências web, se torna necessário refletir sobre a flexibilidade de acesso pelos estudantes. Muitos encontram dificuldades de acesso em determinados horários em função dos reflexos da Pandemia, muitos familiares com as quais o estudante convive em sua residência, também necessitam do acesso à internet pelos mais variados motivos, o que acaba por prejudicar a qualidade da transmissão da aula online em determinados horários (CARDOSO; SANTO, 2020).

Paralelamente a estes problemas apresentados, outro aspecto que não pode ser ignorado é o acesso às tecnologias digitais pelos estudantes. Embora a maior parte da população brasileira tenha acesso à internet e suas ferramentas tecnológicas, de acordo com Lavado (2019), não se pode desconsiderar a camada mais pobre da população e os habitantes localizados nas zonas rurais no país. A falta de políticas públicas para a inclusão digital de milhares de brasileiros que, atualmente, estão fora do ciberespaço impacta diretamente na democratização da educação, ampliando as desigualdades sociais e promovendo a elitização do conhecimento.

Segundo Santo e Dias Trindade (2020, p.165), outro fator importante que os professores devem considerar é definir a estruturação e orientações sobre trabalhos individuais, permitindo mais autonomia ao aluno no momento de realização desta atividade, "que compreenda não só o acesso às plataformas digitais, mas também o trabalho com os materiais físicos de que dispõem nas suas casas". A adequação temporal das atividades decorrentes dos conteúdos apresentados na disciplina ministrada deve ser realista. Se a multiplicidade de tarefas e trabalhos não é uma boa opção pedagógica no ensino presencial, muito menos será quando a forma de aprendizagem estiver sendo realizada de forma remota em casa.

$\mathrm{Na}$ atual situação em que se vive em função de restrições impostas pela Pandemia, o Ensino Remoto de caráter emergencial, tornou-se uma realidade, porém um modelo temporário utilizado em função de circunstâncias desta crise. As soluções encontradas até o presente momento, não foram recriar um sistema educacional online, mas fornecer acesso à educação de maneira rápida durante este período de emergência (MOREIRA; SCHLEMMER, 2020).

\subsection{Categorias de análise}

Para apresentar a proposta de utilização do Telegram como recurso de apoio metodológico na disciplina de Contabilidade Tributária foram utilizadas as categorias de análise segmentadas nas etapas do descrever, do informar, do confrontar e do reconstruir (SMYTH, 1992; LIBERALI, 2004).

\subsubsection{Categoria descrever}

Na categoria do "descrever" se busca a apresentação das ações em forma de texto, de modo que sejam registradas evidências concretas da prática (LIBERALI, 2004).

A aplicação do aplicativo Telegram, conforme já mencionado, ocorreu ao longo de quatro encontros da disciplina de contabilidade tributária, especificamente, direcionadas ao tema ICMS - Imposto sobre a Circulação de Mercadorias e Serviços, em que foram trabalhadas situações problemas envolvendo a DIFAL - Diferencial de alíquotas nas vendas consumidores finais e nas aquisições de bens para o ativo imobilizado das empresas.

Nesse momento, foram organizados os planejamentos das aulas, conforme a Figura 1.

Figura 1 - Encontros realização de atividades

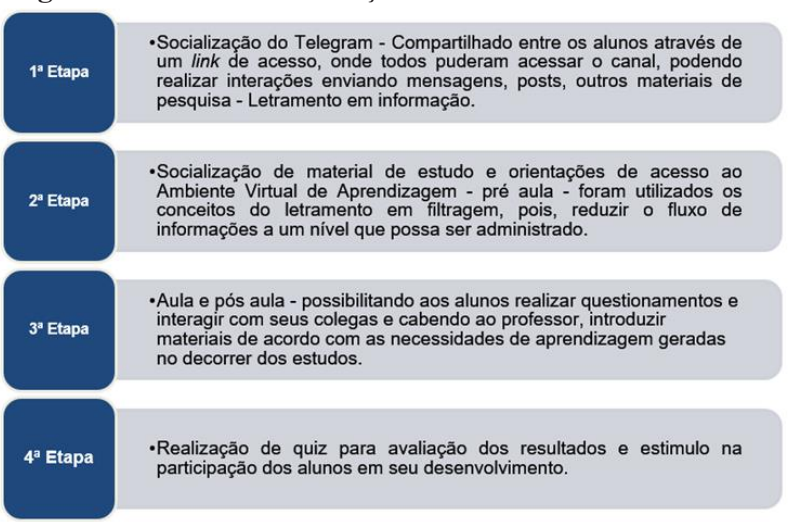

Fonte: os autores.

Para essa organização foi levado em conta a ementa da disciplina, visto que nessa constam os conteúdos como o planejamento tributário, desenvolvimento de conceitos sobre os tributos, suas formas de apuração e contabilização, conceitos dos diferentes regimes de tributação disponíveis para as empresas, simulação de atividades contábeis propostas pelo professor responsável, interação e troca de informações com profissionais do setor contábil. Diante disso, opta-se pela sala de aula invertida, as etapas, as quais foram realizadas por meio de um encontro síncrono pelo Google Meet, e atividades assíncronas por meio do Telegram podem ser retratadas na Figura 2.

Figura 2 - Etapas por meio de encontros síncronos e assíncronos (Ferramenta Telegram)

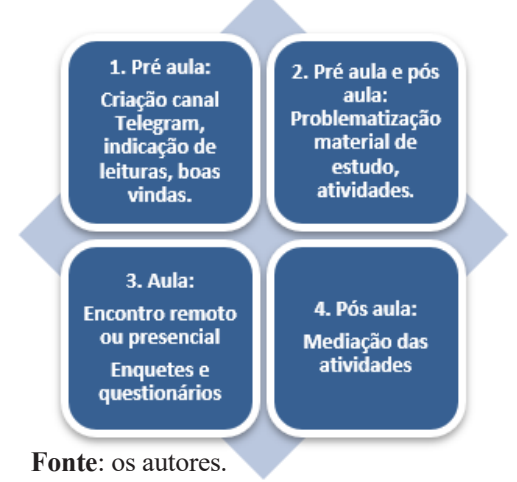


A compreensão detalhada do funcionamento da atividade, alinhando-se a teorias balizadoras, é objeto da próxima categoria: o informar.

\subsubsection{Categoria Informar}

$\mathrm{Na}$ categoria do "informar" foram buscados os princípios que embasam as ações, as teorias que sustentam a prática efetivada pelo professor (LIBERALI, 2004).

Assim, iniciam-se as ações apresentando ao aluno o Telegram, contextualizando que foi fundado em 2013 pelos irmãos Nikolai e Pavel Durov, caracterizado com um serviço de mensagens instantâneas baseado na nuvem, está disponível para smartphones, tablets e desktops. Neste aplicativo é permitido ao usuário a troca de mensagens, fotos, vídeos e arquivos de qualquer tipo, possibilitando a comunicação entre professor e aluno no compartilhamento de informações e materiais de aula.

Pontua-se que, da mesma forma como o Whatsapp, seu concorrente direto, o Telegram precisa de um número de telefone para ser utilizado, porém os clientes deste aplicativo possuem código aberto, permitindo o uso de APIs ${ }^{1}$ para desenvolvedores independentes. Outra característica diferenciadora se refere aos grupos criados neste aplicativo, enquanto seu concorrente limita a quantidade de membros em um grupo para até 256 pessoas, no Telegram cada grupo pode chegar até 200.000 membros. Nesse momento, é preciso auxiliar os alunos no processo de conhecer e navegar no aplicativo.

Tais ações remetem aos estudos que apontam que o ensino, quando realizado com a introdução de metodologias ativas, transforma-se em um processo de mediação, deixando em segundo plano a transmissão conhecimento como na metodologia expositiva, dando maior ênfase à construção do conhecimento. Segundo Althaus e Bagio (2017, p.86), “o professor atua como mediador: problematiza o conteúdo, faz perguntas, intervém nas atividades discentes, dialoga, aprende ao ensinar".

Mostra-se para os alunos que o uso do Telegram, como ferramenta tecnológica, foi introduzido para dar apoio à utilização de metodologias ativas de ensino, possibilitando a mediação e acompanhamento dos discentes durante o desenvolvimento da disciplina.

Outra justificativa foi a necessidade de alteração na forma de ensino, e, por conseguinte, a mudança na arquitetura e rotina escolar, em função da Pandemia causada pelo Corona vírus (COVID 19), visto que houve alteração nas rotinas de ensino do professor, no desenvolvimento de materiais e nas ações metodológicas.

Respalda-se, ainda, as ações nos estudos de Althaus (2016), visto que indicam profícua a utilização de metodologias ativas, pois permite investir na autoavaliação e coavaliação dos discentes, integrando a avaliação aos processos de ensino e aprendizagem na perspectiva formativa, apostando no desenvolvimento da autonomia dos acadêmicos.

Nesse contexto, o desafio consistiu em estimular a reflexão sobre o processo de formação, incentivando o próprio aluno a adotar o Telegram, o usando como uma prática inerente das metodologias ativas, sendo como uma ferramenta útil para a aproximação entre o professor-conteúdo-demais alunos.

Para o desenvolvimento da disciplina e utilização do Telegram como ferramenta de apoio tecnológico, fez-se necessário a abordagem de Letramentos Digitais. A concepção de Letramento Digital que se está assumindo provém dos estudos de Dudeney, Hockly e Pegrum (2016, p.17), autores que definem os letramentos digitais como um conjunto de "habilidades individuais e sociais necessárias para interpretar, administrar, compartilhar e criar sentido eficazmente no âmbito crescente dos canais de comunicação digital".

Entre os vários letramentos apresentados pelos autores Dudeney, Hockly e Pegrum (2016), foram eleitos os letramentos digitais chave com foco na informação, formada pelo conjunto de quatro letramentos digitais, no Quadro 1, apresentados os conceitos dos letramentos com foco na informação.

Quadro 1 - Letramentos digitais (Foco na Informação)

\begin{tabular}{|c|l|}
\hline $\begin{array}{c}\text { Letramento } \\
\text { classificatório }\end{array}$ & $\begin{array}{l}\text { A classificação de recursos úteis é uma forma } \\
\text { de manter a atenção nesses, acrescentando } \\
\text { termos descritivos ou etiquetas (metadados). } \\
\text { Os usuários da informação podem clicar nessas } \\
\text { etiquetas, que funcionam como hiperlinks, } \\
\text { direcionando a outros recursos salvos. }\end{array}$ \\
\hline Letramento \\
em pesquisa & $\begin{array}{l}\text { Poucas pessoas têm habilidade em escolher } \\
\text { palavras-chave apropriadas para sua pesquisa, } \\
\text { em função de limitações de conhecimento } \\
\text { sobre o alcance que os motores de busca } \\
\text { possuem, os quais pendem suas buscas para } \\
\text { o lado comercial, popular e o mais recente, } \\
\text { retornando resultados mais personalizados de } \\
\text { acordo com o que seria interessante para o } \\
\text { pesquisador. Confiar em um único buscador } \\
\text { como o Google seria como dar autorização } \\
\text { a ele sobre o que seria, de fato, importante e } \\
\text { relevante no mundo. Saber a diferença entre } \\
\text { o que é confiável ou não, é uma questão de } \\
\text { desenvolver o letramento em informação. }\end{array}$ \\
\hline $\begin{array}{c}\text { Letramento } \\
\text { em filtragem }\end{array}$ & $\begin{array}{l}\text { Considerado um dos principais letramentos } \\
\text { contemporâneos, onde o senso crítico, ou seja, } \\
\text { a habilidade de avaliar documentos e artefatos } \\
\text { possa ser administrado é uma das características } \\
\text { através de perguntas, avaliando a credibilidade, } \\
\text { comparanento. } \\
\text { informação. fontes e rastreando as origens da }\end{array}$ \\
\hline Fonte: adaptado de Dudena
\end{tabular}
Fonte: adaptado de Dudeney, Hockly e Pegrum (2016).

A utilização dos letramentos supracitados se faz necessário, segundo Moran (2005), pois as redes e, principalmente, a internet provocaram mudanças profundas na educação presencial e à distância. No futuro, a pesquisa deve ceder espaço ao trabalho em rede, portanto, será muito importante

1 API provém do inglês Application Programming Interface, conjunto de rotinas e padrões estabelecidos por um software para utilização de suas funcionalidades por aplicativos que não pretendem envolver-se em detalhes, mas apenas usar seus serviços. 
orientar os estudantes na construção de redes pessoais de aprendizagem.

De acordo com Dudeney, Hockly e Pegrum (2016), o letramento digital com foco na informação é um dos mais importantes entre os letramentos contemporâneos, pois as informações consideradas relevantes estão cada vez mais disponíveis, graças à internet móvel. A utilização dessa tecnologia tornou menos importante memorizar a informação, mas em contrapartida, novas habilidades devem ser desenvolvidas ao acessar, avaliar e administrar conteúdo.

Dentro das ações dessa categoria, contempla-se a etapa de socialização do canal do Telegram e as instruções iniciais. Assim, de acordo com o primeiro item da Figura 2, a pré aula foi precedida pela criação do canal do Telegram denominado como "Contabilidade Tributária I", devidamente compartilhado entre os alunos através de um link de acesso, por meio do qual todos puderam acessar o canal, podendo realizar interações enviando mensagens, posts, outros materiais de pesquisa. A seguir se tem a Figura 3, ilustrando a criação do canal, apresentação da disciplina e socialização dos primeiros materiais de pesquisa.

Figura 3 - Canal no Telegram e Apresentação dos Materiais

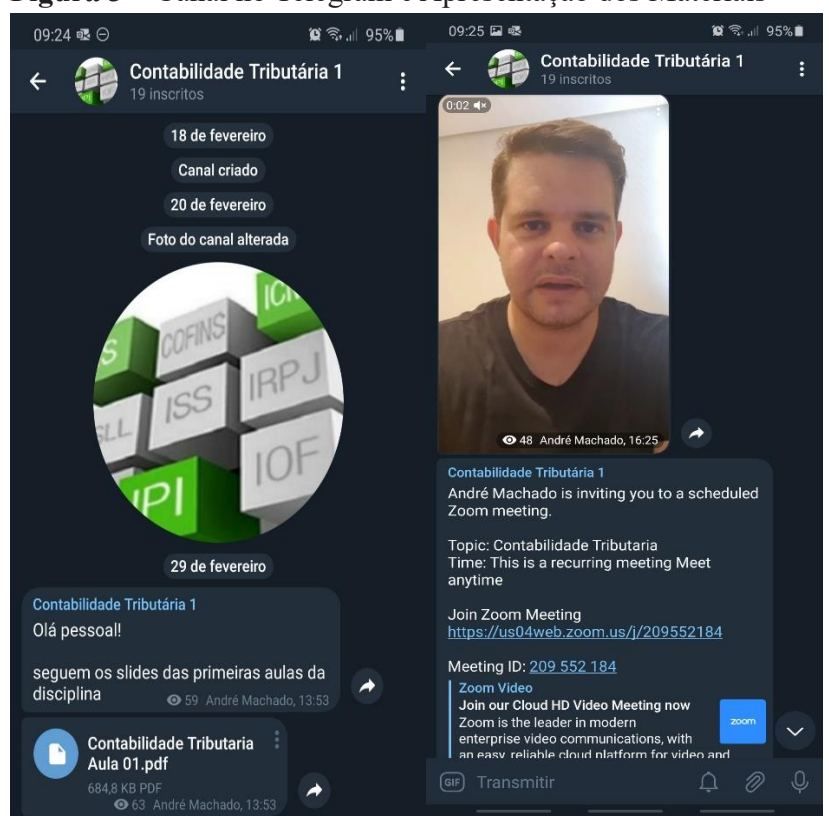

Fonte: os autores.

Nesta primeira etapa foram utilizados os conceitos dos letramentos digitais, pois saber a diferença entre o que é confiável ou não, é uma questão de desenvolver o letramento em informação, segundo November (2009), os estudantes que não entendem a gramática básica da internet serão manipulados por pessoas que a entendem.

Dessa forma, por meio de materiais de pesquisa socializados no canal Telegram, os alunos foram orientados sobre como realizar pesquisas de forma correta, buscando informações em sites governamentais do Palácio do Planalto e do Senado Federal e em alguns casos em sites comerciais que realmente puderam contribuir para o desenvolvimento dos estudos, estabelecendo comparativos entre a legislação oficial e outras fontes de pesquisa disponibilizadas nos buscadores da internet.

Neste caso, justifica-se a importância do letramento em informação, considerado um dos principais letramentos contemporâneos, em que o senso crítico, ou seja, a habilidade de avaliar documentos e artefatos através de perguntas, avaliando a credibilidade, comparando fontes e rastreando as origens da informação. Na disciplina de Contabilidade Tributária, esta forma de letramento é essencial, pois os alunos devem aprender a selecionar as fontes de informação a respeito da legislação tributária.

A seguir, passou-se para Socialização de material de estudo e orientações de acesso ao Ambiente Virtual de Aprendizagem. No segundo e terceiro item da Figura 3, em que constam os elementos como pré-aula, aula e pós-aula, foram utilizados os conceitos do letramento em filtragem, pois reduzir o fluxo de informações a um nível que possa ser administrado é uma das características deste letramento. A seguir, na Figura 4, se tem a imagem das orientações sobre o acesso ao AVA e a legislação específica que foi utilizada para a resolução da atividade proposta aos alunos.

Figura 4 - Acesso ao Material e Legislação / Letramento em Filtragem

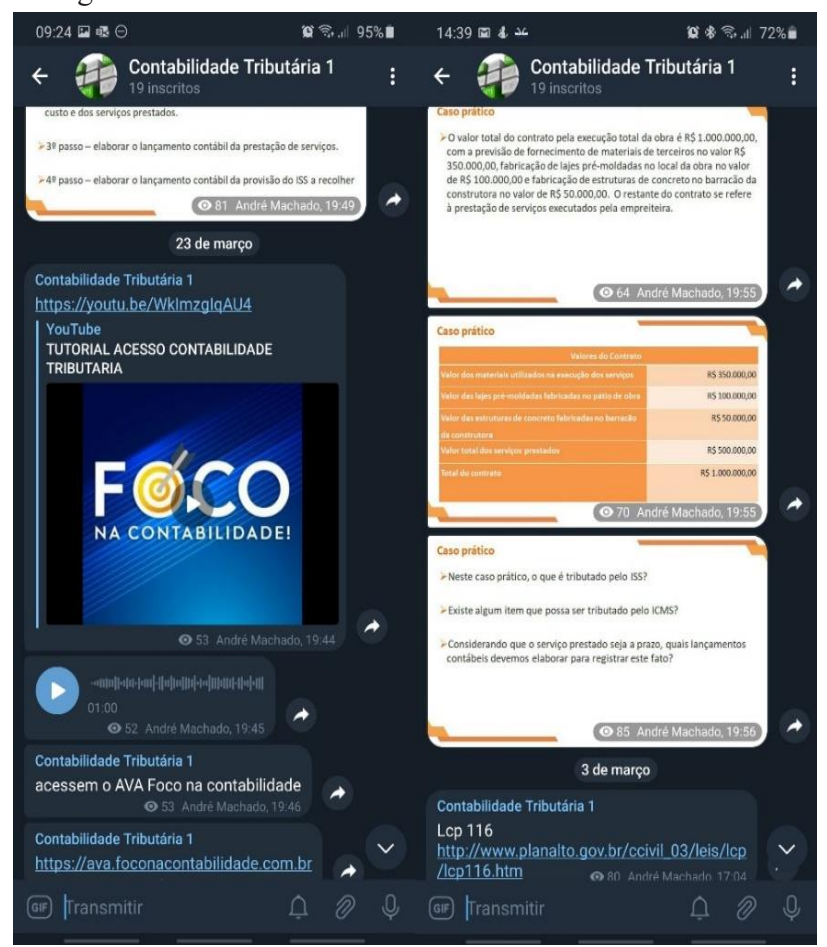

Fonte: os autores.

Nesta etapa, os alunos foram estimulados a realizar uma pesquisa com os temas discutidos nos materiais e, em aula, os quais serviram de pesquisa, em que foi possível "filtrar" todas as informações, utilizando o material que realmente contribuiu para a resolução da atividade.

Justifica-se a adoção dos conceitos do letramento em filtragem, pois no futuro, a pesquisa deve ceder espaço ao 
trabalho em rede, portanto, será muito importante orientar os estudantes na construção de redes pessoais de aprendizagem. Nesse sentido, o Telegram pode suprir todas as necessidades geradas durante o desenvolvimento da disciplina, possibilitando aos alunos realizar questionamentos e interagir com seus colegas e cabendo ao professor, introduzir materiais de acordo com as necessidades de aprendizagem geradas no decorrer dos estudos.

Assim, o Telegram enquanto ferramenta de apoio tecnológico, realizou esse papel, possibilitando tanto ao docente, quanto as discentes, a criação de uma rede de informações, encurtando distâncias e promovendo interações com características das metodologias ativas e do ensino híbrido.

Dando prosseguimento, passa-se para a realização de quiz para estimular a interação e participação dos alunos no decorrer da aula. De acordo com o que foi inicialmente demonstrado, no item 4 da Figura 2, a utilização da ferramenta possibilitou ganhos expressivos quanto à mediação de conteúdo da disciplina, permitindo a troca de informações e direcionamentos realizados pelo professor, conforme a participação dos alunos em seu desenvolvimento. Foram realizados enquetes e questionários por meio do Telegram, os quais permitem aos alunos utilizar o conteúdo da disciplina na resolução de atividades. A seguir, se tem na Figura 5, a demonstração de um quiz que foi utilizado durante a aula, estimulando os alunos a testar seu nível de conhecimento adquirido:

Figura 5 - Quiz com perguntas sobre Contabilidade Tributária

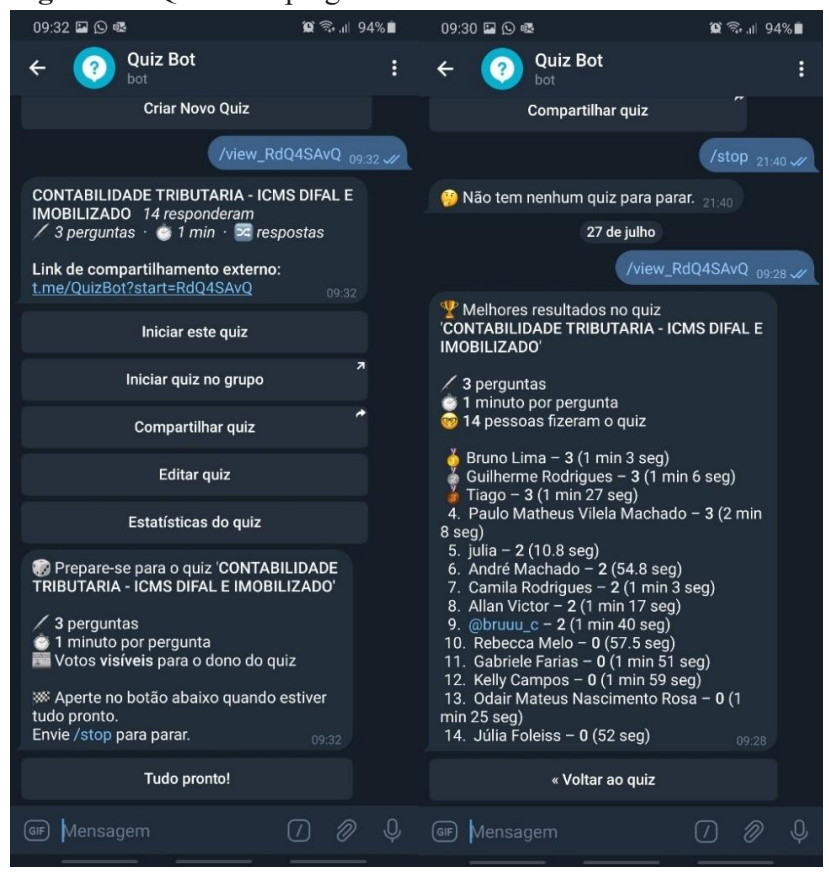

Fonte: os autores.

Neste quiz, os alunos foram submetidos a três perguntas sobre o tema discutido em um dos encontros síncronos da disciplina, sendo que as perguntas e suas respectivas alternativas foram sorteadas de forma aleatória pelo sistema do Telegram, possibilitando um desafio ainda maior aos alunos, pois o tempo de resposta foi de apenas um minuto para cada um dos questionamentos.

O acesso ao quiz foi realizado por meio de um link compartilhado pelo professor dentro do canal criado no Telegram, alguns alunos relataram dificuldades de acesso no primeiro momento da atividade, portanto, fez-se necessário uma breve explicação sobre como participar da atividade e foi estipulado um tempo total de realização em cinco minutos.

Após a realização da atividade, foi possível acessar os resultados divulgados pelo quiz do Telegram, em que foram verificados o tempo utilizado por cada aluno em sua respectiva participação e a quantidade de respostas corretas, permitindo ao professor de um feedback instantâneo sobre o nível de interação dos alunos com o conteúdo da disciplina.

Para fins de transposição didática foram explicadas as etapas anteriormente descritas quanto ao uso do Telegram como ferramenta tecnológica de apoio a aula remota: a) Primeira etapa: Socialização do canal e instruções iniciais; b) Segunda etapa: Socialização de material de estudo e orientações de acesso ao Ambiente Virtual de Aprendizagem; c) Terceira etapa: Questionamentos, interação e participação dos alunos; d) Realização de quiz para avaliação do nível de aprendizagem dos alunos.

\subsubsection{Categoria Confrontar}

$\mathrm{Na}$ categoria do "confrontar", o intuito é colocar a prática realizada pelo professor em contraste com aspectos contextuais, a partir da submissão das ações a questionamentos (LIBERALI, 2004).

Nesse sentido, a opção aqui delineada é a de que esse contraste seja realizado a partir de uma espécie de balanço entre o que foi planejado e o que foi concretizado. E, nesse processo, um aspecto que chamou a atenção do professor foi o tempo despendido para explicar aos alunos como utilizar a ferramenta Telegram, seus recursos e possiblidades de uso dentro da disciplina.

Conforme mencionado anteriormente, durante a fase de pré-aplicação da proposta, ocorreu o planejamento, com a seleção dos materiais e a legislação tributária específica e a elaboração dos desafios e roteiros. Nesta fase, o pensamento básico era já no início da disciplina, durante a aula de 60 minutos, separar 10 minutos para apresentação da ferramenta Telegram e como seriam realizadas as interações e socializações de conteúdo durante as aulas, 30 minutos para explanação do conteúdo da disciplina, 5 minutos para realização do quiz e 15 minutos para fechamento da aula e avaliação dos resultados de aprendizagem dos alunos.

Embora o professor soubesse que 10 minutos de introdução e apresentação sobre a ferramenta tecnológica de suporte fossem longos, fez-se necessário em função da falta de letramentos digitais por parte dos alunos no que se refere às formas de interação e socialização dos materiais e atividades da disciplina. Portanto, a distribuição de tempo foi necessária 
para dar mais autonomia e protagonismo aos alunos no momento de realização da atividade quiz, em contrapartida menor tempo de mediação do professor.

No segundo momento da aula, houve o momento de explanação sobre o seu conteúdo, socialização de materiais e discussão no momento de perguntas. Logo após, em seu terceiro momento, foram separados 5 minutos para a interação quiz, o qual precisou ser estendido para 10 minutos em função da quantidade de alunos apresentando dificuldades de acesso e realização da atividade programada, acarretando maior tempo despendido pelo professor em uma espécie de mediação recorrente apenas para resolução de problemas. As dúvidas e problemas de acesso foram resolvidos, mas faltou tempo para fechamento da aula e avaliação dos resultados e discussão sobre as percepções dos alunos.

São essas inconsistências entre o planejado e o executado que, por vezes, leva à necessidade de ajustamento de uma proposta, cuja discussão é o foco da última categoria: o reconstruir.

\subsubsection{Reconstruir}

Por fim, na categoria do "reconstruir", considera-se que uma prática não é algo imutável, com a busca de alternativas para a execução de certas ações (LIBERALI, 2004).

No caso da aplicação do aplicativo Telegram enquanto ferramenta de suporte tecnológico, conforme apresentado, acredita-se que o processo apresentou resultados muito satisfatórios, evidenciando a possibilidade de remodelação das tradicionais aulas de contabilidade tributária.

Em linhas gerais, o aplicativo se mostrou exequível, alinhado com os objetivos da disciplina, além de promover o acesso dos alunos de forma mais interativa aos materiais socializados conhecimentos por meio de processos diferenciados. Dessa forma, os principais ajustes a serem efetuados para a reconstrução da proposta residem, justamente, conforme discutido, nos quesitos mediação e tempo.

No que tange à mediação, o procedimento a ser remodelado está na elaboração de roteiros a serem disponibilizados no canal criado para a disciplina, com a inserção de vídeos explicativos capazes de preencher eventuais lacunas identificadas pelos alunos no momento de participação do quiz.

Em relação ao tempo, a ideia é que os vídeos explicativos sobre participação e utilização do aplicativo e seus recursos, possa ser compartilhado, de forma antecipada, para dar aos alunos maior autonomia no momento de participação das atividades interativas. Nesse caso, por exemplo, o tempo despendido no momento de introdução da aula poderia ser reduzido para 5 minutos, ampliando o tempo para as atividades interativas e fechamento da aula.

Considerando as limitações de tempo, o ideal é que o professor sempre faça uma análise prévia sobre as especificidades de sua disciplina e o grau de dificuldade de seu conteúdo.

\section{Conclusão}

Inicia-se a presente pesquisa, a fim de proceder um relato de experiência sobre a utilização do Telegram, enquanto recurso de apoio metodológico, na disciplina de Contabilidade Tributária, junto ao Ensino Superior. Outro ponto que se apresenta é como as rotinas de ensino do professor, o desenvolvimento de materiais e as ações metodológicas foram afetados, em função da Pandemia causada pelo Corona vírus (COVID 19).

Neste relato foram destacados como o ensino remoto emergencial tem sido utilizado e quais ferramentas tecnológicas podem dar suporte ao desenvolvimento da disciplina sem prejudicar a aprendizagem dos alunos, para isso, foram utilizados os recursos oferecidos pelo aplicativo de troca de mensagens instantâneas Telegram, o qual permite a criação de canais de comunicação entre professores e alunos, de forma a estimular a interação e socialização de materiais, formando uma rede social de ensino e aprendizagem consistente.

Após análise da práxis docente, de forma sumarizada, observa-se, por meio dos estudos teóricos realizados que o Telegram: a) mantêm os alunos conectados e integrados aos assuntos da disciplina, com materiais socializados e devidamente direcionados pelo professor; b) auxilia o educando no desenvolvimento de atividades propostas, resolução de dúvidas sem precisar esperar o próximo encontro; c) mantém os estudantes motivados estimulando a competitividade por meio de atividades realizadas durante a aula remota, em que foram realizados questionários na modalidade quiz, recurso este que também serviu como avaliação do nível de aprendizagem dos alunos.

Cabe ressaltar que as etapas de introdução do Telegram nas rotinas de estudo dos alunos devem ser devidamente adaptadas pelo professor, de acordo com a finalidade, o contexto e o público-alvo da escola ou Instituição de Ensino Superior em que atua.

Assim, enquanto docentes responsáveis pela disciplina de Contabilidade Tributária, por meio deste relato de experiência, observa-se uma melhora na aprendizagem dos alunos, visto que o aplicativo enquanto ferramenta tecnológica de suporte as metodologias ativas, estimula as interações e compartilhamento de informações, tornando-se em uma verdadeira rede social de aprendizagem.

Diante do que foi apresentado foi feito convite para outros pesquisadores e professores do Ensino Superior a investigarem o uso deste e outros aplicativos, como ferramentas de ensino, de forma a propiciar o aumento de recursos didáticos disponíveis e adequados a esta ferramenta para trabalhos futuros.

\section{Referências}

ALTHAUS, M.T.M. Metodologias de Ensino na prática pedagógica universitária: reflexões iniciais. Campo Grande: Universidade Católica Dom Bosco, 2016.

ALTHAUS, M.T.M.; BAGIO, V.A. As metodologias ativas e as aproximações entre o ensino e a aprendizagem na prática 
pedagógica universitária. Rev. Doc. Ensino Sup., v.7, n.2, p.7996, 2017. doi: https://doi.org/10.35699/2237-5864.2017.2342.

BAUER, M.W.; GASKELLl, G. Pesquisa qualitativa com texto, imagem e som: um manual prático. Petrópolis: Vozes, 2017.

BACICH, L.; MORAN, J. Aprender e ensinar com foco na educação híbrida. Rev. Pátio, n.25, p.45-47, 2015.

BACICH, L.; TANZI NETO, A.; TREVISANI, F.M. Ensino híbrido: personalização e tecnologia na educação. In: BACICH, L.; TANZI NETO, A.; TREVISANI, F.M. (Org.). Ensino híbrido: personalização e tecnologia na educação. Porto Alegre: Penso, 2015. p.47-65.

CARDOSO, A.L; SANTO, E.E. Literacia digital: um mosaico de experiências no contexto da formação docente. In: DIASTRINDADE, S.; MOREIRA, J.A.; FERREIRA, A.G. Pedagogias digitais no ensino superior. Coimbra: CINEP/IPC, 2020.

CARDOSO, A.L. et al. Modelo Pedagógico Virtual UFRB: por uma educação aberta e digital. Cruz das Almas: UFRB, 2018.

CHRISTENSEN, C.M.; HORN, MB.; STAKER, H. Ensino Hibrido: uma inovação disruptiva? uma introdução à teoria dos híbridos. Clayton Christensen Institute, 2013. Disponível em: http://porvir.org/wp-content/uploads/2014/08/PT Is-K-12blended-learning-disruptive- Final.pdf. Acesso em: 2 abr. 2020.

CRESWELL, J.W. Investigação qualitativa e projeto de pesquisa: escolhendo entre cinco abordagens. Porto Alegre: Penso, 2014.

DUDENEY, G.; HOCKLY, N.; PEGRUM, M. Letramentos Digitais. São Paulo: Parábola Editorial, 2016.

FONSECA, S.M.; MATTAR NETO, J.A. Metodologias ativas aplicadas à educação a distância: revisão de literatura. Rev. EDaPECI, v.17, n.2, p.185-197, 2017. doi: https://doi. org/10.29276/redapeci.2017.17.26509.185-197

GARRISON, D.R.; ANDERSON, T.; ARCHER, W. The first decade of the community of inquiry framework: a retrospective. Internet Higher Educ., n.13, p.5-9, 2010. doi: 10.1016/j.iheduc.2009.10.003.

GURI-ROSENBLIT, S. Distance Education in the Digital Age: common misconceptions and challenging tasks. J. Distance Educ., v.23, n.2, p.105-122, 2009.

HOFFMAN, J. Blended learning. USA: ASTD Press, 2011.

LAVADO, T. Uso da internet no Brasil cresce, e $70 \%$ da população está conectada. G1 Economia, 2019. Disponível em: https://glo.bo/3bMOSQQ. Acesso em: 27 abr. 2020.

LÉVY, P. Cibercultura. Rio de Janeiro: Editora 34, 1998.

MORAN, J.M. Avaliação das mudanças que as tecnologias estão provocando na educação presencial e a distância. Rev. Educ. Cultura Contemp., v.2, n.4, p.89-108, 2005.

MORAN, J.M. Educação híbrida: um conceito-chave para a educação. In: BACICH, L.; TANZI NETO, A.; TREVISANI, F.M. (Org.). Ensino híbrido: personalização e tecnologia na educação. Porto Alegre: Penso, 2015.

MOREIRA, J.A. Reconfigurando Ecossistemas Digitais de Aprendizagens com Tecnologias Audiovisuais em Rede. Rev. Educ.Distância, v. 5, n.1, p.5-15, 2018.

MOREIRA, J.A.; SCHLEMMER, E. (2020). Por um novo conceito e paradigma de educação digital onlife. Rev. UFG, v.20, n.2. 2020

MOREIRA, J.A.; DIAS-TRINDADE, S. Comunidades virtuais de aprendizagem. In: JARDIM, J.; FRANCO, E. (Org.) Empreendipédia: dicionário de educação para o empreendedorismo. Lisboa: Gradiva, 2019.

NOVEMBER, A. Empowering students with technology. Corwin Press, 2009.

SANTO, E.E.; DIAS-TRINDADE, S.D. Educação a Distância e Educação Remota Emergencial: Convergências e Divergências. In: MACHADO, D.P. Educação em tempos de Covid-19: reflexões e narrativas de pais e professores. Curitiba: Dialética e Realidade, 2020.

STAKER, H.; HORN, M.B. Classifying K-12 blended learning. Mountain View, CA: Innosight Institute, 2012.

SUNAGA, A.; CARVALHO, C.S. As tecnologias digitais no ensino híbrido. In: BACICH, L.; TANZI NETO, A.; TREVISANI, F.M. (Org.). Ensino híbrido: personalização e tecnologia na educação. Porto Alegre: Penso, 2015. p.141-154.

TOMAZINHO, P. Ensino remoto emergencial: a oportunidade da escola criar, experimentar, inovar e se reinventar. 2020. Disponível em: https://bit.ly/2YkZrqx. Acesso em: 28 abr. 2020.

VALENTE, J.A. Blended learning e as mudanças no ensino superior: a proposta da sala de aula invertida. Educ. Rev., n.4, p.79-97, 2014. doi: 10.1590/0104-4060.38645. 